\title{
REVERSE ORDER LAW FOR WEIGHTED MOORE-PENROSE INVERSES OF MULTIPLE MATRIX PRODUCTS
}

\author{
ZHIPING XIONG AND YINGYING QIN
}

Abstract. In this paper by using some matrix rank theories, we derive equivalent conditions for reverse order law of weighted Moore-Penrose inverses of multiple matrix products. In addition, we also give a variety of necessary and sufficient conditions for the reverse product $\left(A_{n}\right)_{M_{n}, M_{n+1}}^{\dagger}\left(A_{n-1}\right)_{M_{n-1}, M_{n}}^{\dagger} \cdots\left(A_{1}\right)_{M_{1}, M_{2}}^{\dagger}$ to be a $\{1\}-,\{1,2\}-,\left\{1,3 M_{1}\right\}-,\left\{1,4 M_{n+1}\right\}-$, $\left\{1,2,3 M_{1}\right\}$ - or $\left\{1,2,4 M_{n+1}\right\}$-inverse of matrix product $A_{1} A_{2} \cdots A_{n}$.

Mathematics subject classification (2010): 15A03, 15A09, 15A24.

Keywords and phrases: Reverse order law, generalized inverse, weighted generalized inverse, elementary block matrix operations, matrix rank theory.

\section{REFERENCES}

[1] A. Ben-Israel and T. N. E. Greville, Generalized Inverses: Theory and Applications, WileyInterscience, 1974, 2nd Edition, Springer-Verlag, New York, 2002.

[2] D. T. BARWICK AND J. D. GILBERT, On generalization of the reverse order law with related results, SIAM J. Appl. Math. 27 (1974), 326-330.

[3] D. S. DJORDJEVIĆ, Furthuer results on the reverse order law for generalized inverses, SIAM J. Matrix. Anal. Appl. 29 (2007), 1242-1246.

[4] T. N. E. GREVILLE, Note on the generalized inverse of a matrix product, SIAM Review 8 (1966), $518-521$.

[5] R. E. Hartwig, Block generalized inverses, Arch. Rational. Mech. Anal. 61 (1976), 197-251.

[6] Q. LIU AND M. WEI, Reverse order law for least squares g-inverses of multiple matrix products, Linear and Multilinear Algebra 56 (2008), 491-506.

[7] G. Mars Aglia AND G. P. H. STYAn, Equalities and inequalities for ranks of matrices, Linear and Multilinear Algebra 2 (1974), 269-292.

[8] R. Penrose, A generalized inverse for matrices, Proc. Cambridge. Philos. Soc. 51 (1955), 406-413.

[9] C. R. RaO And S. K. Mitra, Generalized Inverse of Matrices and Its Applications, Wiley, New York, 1971.

[10] W. Sun AND Y. WeI, Inverse order rule for weighted generalized inverse, SIAM J. Matrix Anal. Appl. 19 (1998), 772-775.

[11] Y. TIAN, Reverse order laws for generalized inverse of multiple matrix products, Linear Algebra Appl. 211 (1994), 85-100.

[12] G. Wang, Y. We and S. Qiao, Generalized Inverses: Theory and Computations, Science Press, Beijing, 2004.

[13] G. WAng And B. Zheng, The reverse order law for the generalized inverse $A_{T, S}^{(2)}$, Appl. Math. Comput. 157 (2004), 295-305.

[14] M. WEI, Reverse order laws for generalized inverse of multiple matrix products, Linear Algebra Appl. 293 (1999), 273-288.

[15] M. WAng, M. Wei And Z. JiA, Mixed-type reverse order law of $(A B)^{(1,3)}$, Linear Algebra Appl. 43 (2009), 1691-1699. 
[16] Z. XIONG AND B. Zheng, The reverse order laws for $\{1,2,3\}$ - and $\{1,2,4\}$-inverses of two matrix product, Appl. Math. Let. 21 (2008), 649-655.

[17] B. Zheng AND Z. XIONG, An new equivalent condition of the reverse order law for $g$-inverses of multiple matrix products, Electronic Journal of Linear Algebra 17 (2008), 1-8.

[18] B. ZHENG AND Z. Xiong, On reverse order laws for the weighted generalized inverse, Arab. J. Sci. Eng. 34 (2A) (2009), 195-203.

[19] S. ZLOBEC, An explicit form of the Moore-Penrose inverse of an arbitrary complex matrix, SIAM Review 12 (1970), 132-134. 